\title{
Persoonlijkheid en Hersenconnectiviteit, een nieuwe uitdaging?
}

Labooy-Speksnijder, C. ${ }^{1}$, Deijen, J.B. ${ }^{1,2}$, Engelbregt, H.J. ${ }^{2,3}$

${ }^{1}$ Vrije Universiteit, Sectie Klinische Neuropsychologie, Amsterdam

${ }^{2}$ Hersencentrum, Amsterdam

${ }^{3}$ Ludwig-Maximilian Universiteit, München, Duitsland

Correspondentieadres:

j.b.deijen@vu.nl

\section{Samenvatting}

In deze pilot studie wordt een poging gedaan om persoonlijkheid te relateren aan hersenactiviteit en hersenconnectiviteit. Voor de hersenactiviteit werden twee correlatiematen berekend die zijn gebaseerd op hersengolven, namelijk: intra-persoonlijke correlatie (samenhang linker- en rechterhemisfeer) en interpersoonlijke correlatie (samenhang EEG activiteit persoon $\mathrm{A}$ en persoon $\mathrm{B}$ ).

Hypothesen: (1) Er bestaat een relatie tussen individuele persoonlijkheidsfactoren en intra- of interpersoonlijke correlatie. (2) Er bestaat een relatie tussen een overeenkomst in persoonlijkheid en interpersoonlijke EEG correlatie.

Methoden: Hiervoor werd bij 14 proefpersonen (10 vrouwen) tussen de 19 en 24 jaar de HEXACO-SPI persoonlijkheidsvragenlijst afgenomen en werd er EEG gemeten tijdens rust (ruststaat EEG). Deze ruststaat EEG werd vergeleken met het EEG tijdens een sociale interactie.

Resultaten: In rust bleek de persoonlijkheidsfactor emotionaliteit een significante invloed te hebben op de intra-persoonlijke EEG correlatie. Dat wil zeggen, hoe hoger de score op Emotionaliteit des te groter de correlatie tussen het EEG van de linker en rechter hemisfeer. Mogelijk staat dit in verband met onzekerheid en een verhoogd zelfbewustzijn. Er zijn geen 
Labooy-Speksnijder et al. Persoonlijkheid en Hersenconnectiviteit, een nieuwe uitdaging?

overige relaties met persoonlijkheid of overeenkomst in persoonlijkheid tussen koppels gevonden.

Relevantie: Deze studie één van de eerste pogingen om een directe neurofysiologische relatie tussen connectiviteit en persoonlijkheid te onderzoeken. Onderzoek hiernaar is van belang om de neurale processen die onderhevig zijn aan cognitief functioneren en sociale gedragingen te ontdekken. De door ons gebruikte methoden zijn daarnaast eenvoudig toe te passen voor grootschaliger studies.

\section{Inleiding}

"De mens is een sociaal wezen en kan alleen in de burgergemeenschap zijn volmaaktheid vinden"; aldus Aristoteles. Sindsdien en ook al daarvoor zijn er oneindig veel pogingen gedaan om de relatie tussen het individu en de sociale omgeving te doorgronden.

De nadruk lag hierbij lange tijd op intrapersoonlijke dynamiek tijdens sociale situaties. De laatste jaren zien we een toegenomen interesse in het meten van coherentie tussen de hersenactiviteit van meerdere mensen tegelijkertijd [1]. Dit wordt hyperscanning genoemd [2]. Binnen dit paradigma in de neurowetenschap ligt de nadruk op interpersoonlijke (tussen personen) brein-tot-brein interacties $[1,3$, 4].

Eén van de eerste onderzoeken naar hyperscanning, met behulp van fMRI, werd uitgevoerd door Montague et al.. [5]. Zij meenden dat onderliggende neurale gebeurtenissen intrinsiek sterk dimensionaal zijn, terwijl dat niet of in mindere mate geldt voor de verschillende gedragsmaten waarmee de substraten werden gemeten.

Het brein bestaat uit vele neurale netwerken, groepen van neuronen, welke op een functionele manier met elkaar samenwerken. Beide hersenhelften vervullen bepaalde functies (lateralisatie). Zowel lateralisatie als communicatie tussen de hemisferen (via onder meer het corpus callosum) zijn van belang voor de verwerkingscapaciteit van het brein [6]. De mate van samenwerking of connectiviteit tussen corticale gebieden kan worden beschreven als coherentie. Hierbij is coherentie de correlatie tussen signalen als functie van frequentie [7]. Coherentie kan gebruikt worden om de functionaliteit van corticale verbindingen te evalueren en informatie te krijgen over synchronisatie van corticale activiteit. 
Labooy-Speksnijder et al. Persoonlijkheid en Hersenconnectiviteit, een nieuwe uitdaging?

Naast coherentie binnen het brein van één individu (intra-persoonlijke coherentie) kan in theorie de coherentie in hersenactiviteit tussen personen (interpersoonlijke coherentie ofwel hyperscanning) bepaald worden. Hyperscanning zou hiermee een geschikte methode kunnen zijn om te onderzoeken of mensen letterlijk "op dezelfde golflengte" kunnen zitten [8] of dat eerder sprake is van 'gewone' sociale interactie [9]. Om de neurale substraten die onderliggend zijn aan sociale interactie te meten is directe observatie van de link tussen de hersenen van verschillende personen noodzakelijk [10].

Wanneer mensen "op dezelfde golflengte zitten" lijkt het aannemelijk dat persoonlijkheid een belangrijke rol speelt. Onderzoek naar de structuur van persoonlijkheid heeft zes persoonlijkheidsdimensies geïndiceerd, namelijk: integriteit (oprecht, trouw, eerlijk, betrouwbaar), emotionaliteit (overgevoelig, kwetsbaar, instabiel, labiel), extraversie (uitbundig, opgewekt, spontaan, openhartig), verdraagzaamheid (goedmoedig, bedaard, geduldig, mild), consciëntieusheid (zorgvuldigheid) en openheid voor ervaringen (diepzinnig, origineel, filosofisch) [11].

Vele onderzoeken hebben in het verleden al laten zien dat persoonlijkheid in verband staat met diverse anatomische, functionele en biologische processen. Zo is er een relatie tussen persoonlijkheid en hersenstructuur [12], hersenactiviteit [13] en biochemie [14]. Recent onderzoek betrekt steeds vaker het proces van connectiviteit in het brein bij het bestuderen van persoonlijkheid (e.g. [15]). Hoppenbrouwers et al. [16] suggereert dat interhemisferische connectiviteit onderhevig is aan verschillende cognitieve, affectieve en gedragsmatige functies die samen een persoonlijkheidsstijl vormen.

Kennis over de dynamiek van hersenactiviteit tijdens sociale interactie is belangrijk voor het algemene begrip van de sociale interactie tussen mensen. Mogelijk kan kennis over de dynamiek van hersenactiviteit tijdens sociale interactie inzicht bieden teneinde communicatie te verbeteren. Bijvoorbeeld tussen mensen met sociale problemen, de communicatie tussen therapeut en patiënt of samenwerkingsproblemen.

Voor het huidige onderzoek stellen wij 2 hypothesen;

(1) Er bestaat een relatie tussen iemands persoonlijkheid en intra- of interpersoonlijke EEG correlatie, met emotionaliteit als belangrijkste factor. (2) Er bestaat een relatie tussen de mate van 
Labooy-Speksnijder et al. Persoonlijkheid en Hersenconnectiviteit, een nieuwe uitdaging?

overeenkomst in persoonlijkheid van 2 personen en interpersoonlijke EEG correlatie, met extraversie als belangrijkste factor.

Hieraan voorafgaand wordt bekeken of er een relatie is tussen de demografische kenmerken leeftijd en sekse en intra- of interpersoonlijke EEG correlatie. Emotionaliteit wordt gekenmerkt door zorgen, angsten en onzekerheid [12] [17] die zouden kunnen resulteren in een verhoogd zelfbewustzijn $[18,19]$ met mogelijk een verbeterde intraconnectiviteit in het brein als gevolg. Extraverte mensen houden van sociale interactie en begeven zich het liefst in grote groepen [12]. Verwacht wordt daarom dat personen die hoog scoren op extraversie een hoge mate van interpersoonlijke correlatie hebben. Daarnaast wordt verwacht dat mensen die wat betreft persoonlijkheid meer op elkaar lijken, een hogere interpersoonlijke correlatie hebben en dus meer "op dezelfde golflengte zitten”.

\section{Methode}

\subsection{Onderzoeksdesign}

De afhankelijke variabelen in het onderzoek zijn de berekende intra- en interpersoonlijke EEG correlaties. De onafhankelijke variabelen zijn de zes verschillende persoonlijkheidsfactoren en de mate waarin twee proefpersonen in een koppel overeenkomen wat betreft persoonlijkheid.

Het onderzoek bestond uit twee condities: rust en sociale interactie. In beide condities werd zowel de inter- als intrapersoonlijke correlatie berekend ( 2 × 2 design). Er is gebruik gemaakt van een binnenproefpersonen design: elke proefpersoon nam deel aan beide condities.

\subsection{Participanten}

De 14 deelnemers aan deze studie waren Universitaire bachelor studenten Psychologie van de Vrije Universiteit te Amsterdam van 19 tot 24 jaar oud $(\mathrm{M}=$ 21.64, $\mathrm{SD}=1.45)$, waarvan 4 mannen $(28.57 \%)$ en 10 vrouwen $(71.43 \%)$. De groep bestond uit 3 linkshandigen en 11 rechtshandigen. De deelnemers zijn willekeurig in koppels ingedeeld, op voorwaarde dat koppels enkel uit vrouwen ofwel uit mannen bestonden.

\subsection{Materialen}

Voor de EEG-metingen werd gebruik gemaakt van twee Truscan 32-kanaals EEG systemen met 4,096 Hz per kanaal (Deymed Diagnostics, Czech Republic) en een electrodenkap van Electrocap International met 19 elektrodes volgens het 
Labooy-Speksnijder et al. Persoonlijkheid en Hersenconnectiviteit, een nieuwe uitdaging?

10-20 systeem.. In het huidige onderzoek is gekozen voor EEG correlatie. Hiervoor is exact simultaan opnemen van EEG geen vereiste en kon worden gekozen voor handmatig activeren van de EEG apparaten.

De EEG data werd verwerkt door middel van de frequentieanalyse Fast Fourier transform [20].

Er is gebruik gemaakt van de Honestyhumility, Emotionality, Extraversion, Agreeableness, Conscientiousness, Openness to experience, Simplified Personality Inventory (HEXACO-SPI); een vereenvoudigde versie van de HEXACO persoonlijkheidsvragenlijst [21]. Deze vragenlijst bestaat uit 96 items verdeeld over zes dimensies: Integriteit, Emotionaliteit, Extraversie, Verdraagzaamheid, Consciëntieusheid en Openheid voor Ervaringen. De items betreffen uitspraken over hoe iemand is (bijvoorbeeld "Ik werk harder dan anderen", of "Ik leg gemakkelijk contact met vreemden"), waarop volgens een 5punts Likert schaal geantwoord kan worden (helemaal mee oneens - helemaal mee eens).

\subsection{Procedure}

Proefpersonen werden in paren van twee door middel van de elektrode caps aangesloten op het EEG systeem. Tevens werd aan de linkeroorlel een referentieelektrode bevestigd, en aan de rechteroorlel een grondelektrode. De hersenactiviteit is 10 tot 15 minuten lang gemeten terwijl beide proefpersonen enkel voor hen uit keken en stil zaten (basisconditie), en nogmaals 5 minuten terwijl beide proefpersonen met elkaar praatten en elkaar aankeken (praatconditie). Het onderwerp van gesprek mochten de deelnemers zelf bepalen. De vragenlijsten werden achteraf individueel en vanuit huis via internet ingevuld.

\subsection{Statistische analyses}

Door middel van Excel matrices (formule: $=$ CORRELATE) werd per proefpersoon en per conditie de intra-persoonlijke correlatie tussen de linker- en rechterhersenhelft berekend, door de elektroden van de linkerhersenhelft (elektroden FP1, F3, C3, P3, O1, F7, T3 en T5) te correleren met de elektroden van de rechterhersenhelft (elektroden FP2, F4, C4, P4, O2, F8, T4 en T6). Tevens werd er per koppel per conditie een interpersoonlijke correlatie berekend van het gehele brein door de elektroden van de eerste proefpersoon (elektroden FP1, FP2, F3, F4, C3, C4, P3, P4, O1, O2, F7, F8, T3, T4, T5 en T6) te correleren met de elektroden van de 
Labooy-Speksnijder et al. Persoonlijkheid en Hersenconnectiviteit, een nieuwe uitdaging?

tweede proefpersoon (FP1, FP2, F3, F4, C3, C4, P3, P4, O1, O2, F7, F8, T3, T4, T5 en T6). Per koppel werd door middel van Excel matrices (formule: $=$ CORRELATE) ook een correlatiemaat berekend voor de samenhang in persoonlijkheid, op basis van de totaalscores op de zes persoonlijkheidsfactoren.

Voor de continue variabelen is gecontroleerd op normaliteit: scheefheid (skewness) en toppigheid/gepiektheid (kurtosis). Verder werd parametrisch getest met behulp van SPSS Statistics 17.0. Alle variabelen benaderden in voldoende mate de normaalverdeling (statistic/standard error $=[-3,3])$. De relaties tussen de verschillende persoonlijkheidsfactoren en intra- en interpersoonlijke correlaties zijn daarom onderzocht met behulp van

Pearsons product-moment correlatiecoëfficiënt. Significante correlaties zijn verder getoetst door middel van een lineaire regressieanalyse, omdat verwacht werd dat persoonlijkheid een voorspellende waarde heeft voor intra- en interpersoonlijke correlaties. Aan de assumpties voor een lineaire regressieanalyse (normaliteit, homoscedasticiteit) werd voldaan. Voor alle analyses is een alpha-niveau van .05 gebruikt.

\section{Resultaten}

De beschikbare variabelen waren leeftijd, sekse, voorkeurshand, intra-persoonlijke EEG correlatie in de basisconditie (.18-.99, $\mathrm{M}=.64, \mathrm{SD}=.22)$, interpersoonlijke EEG correlatie in de basisconditie (.02-.32, $\mathrm{M}=$ $.16, \mathrm{SD}=.11)$, intra-persoonlijke correlatie in de praatconditie $(.38-.99, \mathrm{M}=.72, \mathrm{SD}=$ $.22)$, interpersoonlijke correlatie in de praatconditie (.38-.99, $\mathrm{M}=.72, \mathrm{SD}=.22)$, integriteit (41-65, $\mathrm{M}=54.43, \mathrm{SD}=7.44)$, emotionaliteit (32-66, $\mathrm{M}=47.64, \mathrm{SD}=$ 10.35), extraversie (39-69, $\mathrm{M}=56.71, \mathrm{SD}$ =7.52), verdraagzaamheid (36-60, $\mathrm{M}=$ 46.57, SD = 8.33), consciëntieusheid (41 $74, \mathrm{M}=55.07, \mathrm{SD}=10.79$ ), openheid voor ervaringen (39-62, $\mathrm{M}=51.43, \mathrm{SD}=6.43)$ en samenhang in persoonlijkheid (-.42-.89, $\mathrm{M}=.31, \mathrm{SD}=.50)$.

Sekse, leeftijd en voorkeurshand hingen niet statistisch significant samen met de intra- en interpersoonlijke correlaties (zie Tabel 1). 
Labooy-Speksnijder et al. Persoonlijkheid en Hersenconnectiviteit, een nieuwe uitdaging?

Tabel 1

Correlaties tussen sekse, leeftijd en voorkeurshand en correlatiematen

\begin{tabular}{lllll}
\hline & Intrapersoonlijk (BC) & Interpersoonlijk (BC) & Intrapersoonlijk (PC) & Interpersoonlijk (PC) \\
\hline Leeftijd & $\mathrm{r}=-.23$ & $\mathrm{r}=-.51$ & $\mathrm{r}=-.22$ & $\mathrm{r}=-.30$ \\
& $\mathrm{p}=.43$ & $\mathrm{p}=.06$ & $\mathrm{p}=.45$ & $\mathrm{p}=.29$ \\
Sekse & $\mathrm{r}=.11$ & $\mathrm{r}=-.27$ & $\mathrm{r}=.06$ & $\mathrm{r}=-.01$ \\
& $\mathrm{p}=.70$ & $\mathrm{p}=.35$ & $\mathrm{p}=.83$ & $\mathrm{p}=.98$ \\
Voorkeurshand & $\mathrm{r}=-.13$ & $\mathrm{r}=.24$ & $\mathrm{r}=-.38$ & $\mathrm{r}=.23$ \\
& $\mathrm{p}=.66$ & $\mathrm{p}=.41$ & $\mathrm{p}=.18$ & $\mathrm{p}=.43$
\end{tabular}

$\mathrm{BC}=$ basisconditie $\mathrm{PC}=$ praatconditie

In verdere analyses zijn deze variabelen dan ook niet langer meegenomen. De gemiddelde intra- en interpersoonlijke correlaties zijn per conditie weergegeven in Figuur 1; de gemiddelde scores op de HEXACO-SPI zijn weergegeven in Figuur 2.

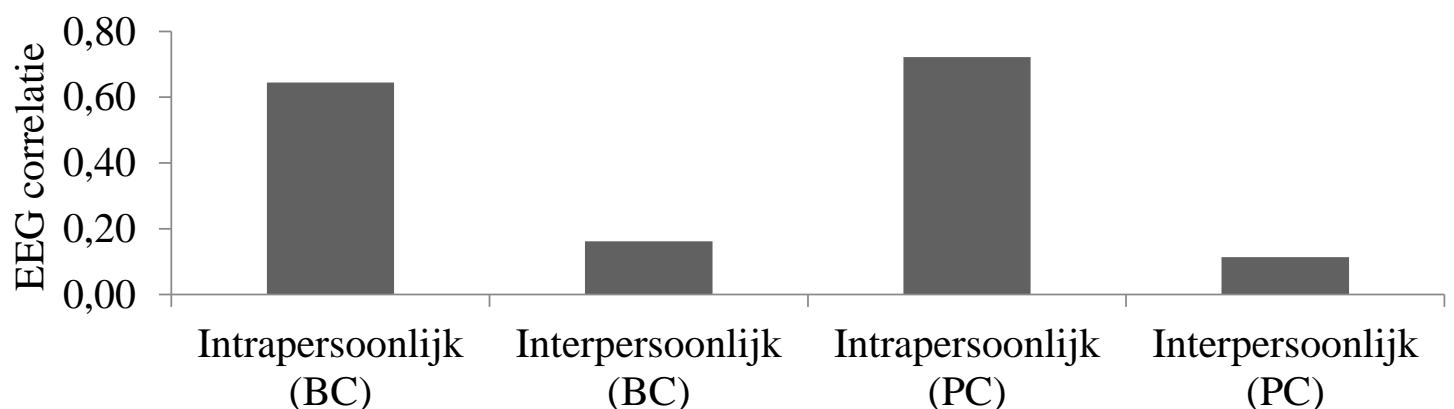

Figuur 1. Gemiddelde intra- en interpersoonlijke EEG correlaties per conditie (BC: basisconditie, PC: praatconditie). 
Labooy-Speksnijder et al. Persoonlijkheid en Hersenconnectiviteit, een nieuwe uitdaging?

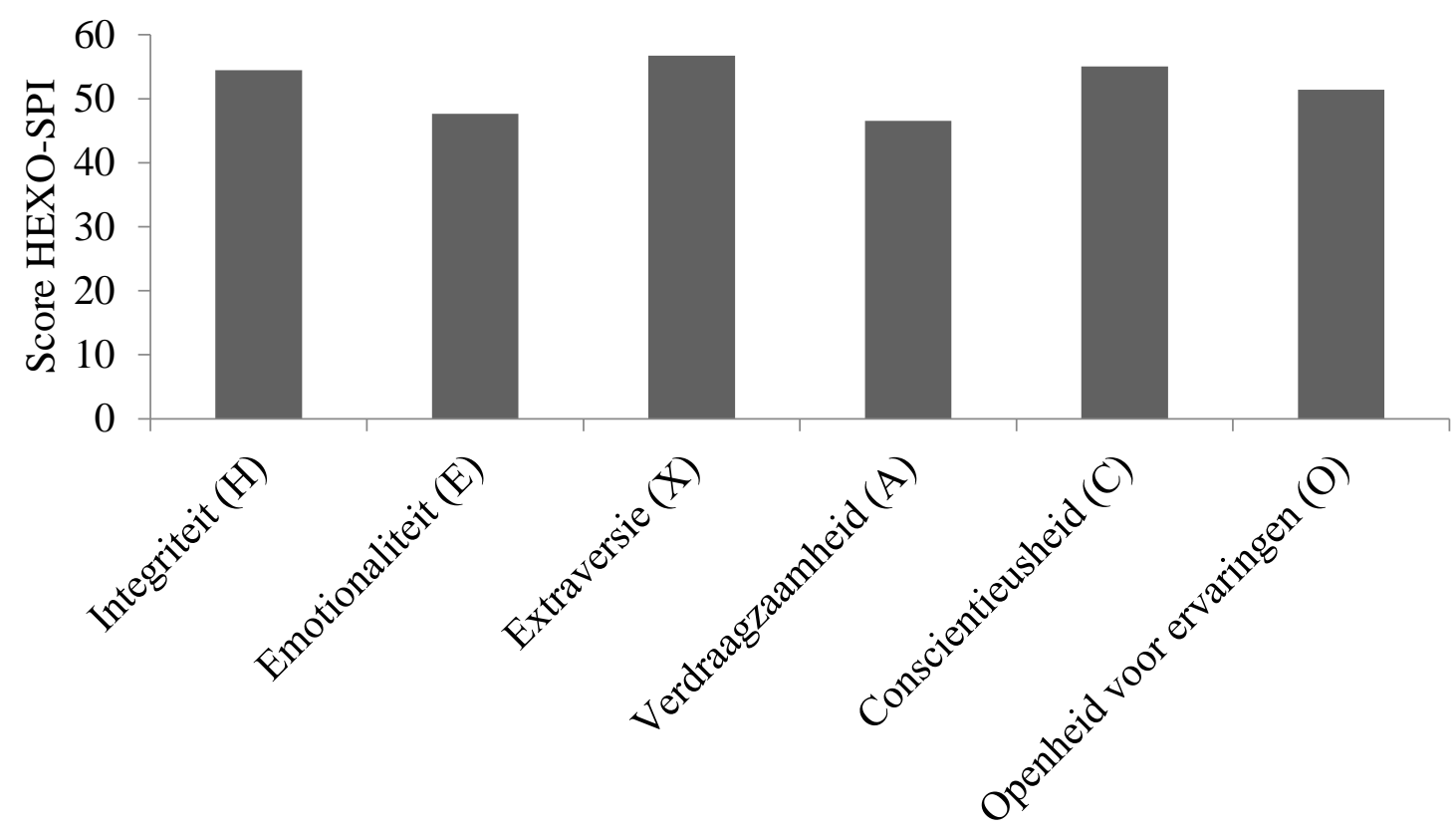

Figuur 2. Gemiddelde scores op persoonlijkheidsfactoren van HEXACO-SPI.

Alle relaties tussen de verschillende intraen interpersoonlijke EEG correlaties en persoonlijkheidsfactoren zijn onderzocht, zowel in de basisconditie (rust) als in de praatconditie. In de basisconditie was er een grote, positieve correlatie tussen intrapersoonlijke EEG correlatie tussen de linker- en rechterhemisfeer en
Emotionaliteit $(\mathrm{r}=.57, \mathrm{n}=14, \mathrm{p}=.03)$.

Dat wil zeggen, hoe hoger de score op

Emotionaliteit des te groter de correlatie tussen het EEG van de linker en rechter hemisfeer. Overige relaties waren niet statistisch significant, zoals te zien is in Tabel 2. 
Tabel 2

Correlaties tussen persoonlijkheidsfactoren en correlatiematen (BC: basisconditie, PC: praatconditie)

\begin{tabular}{lllllll}
\hline & Integriteit & Emotionaliteit & Extraversie & Verdraagzaamheid & Consciëntieusheid & $\begin{array}{l}\text { Openheid voor } \\
\text { ervaringen }\end{array}$ \\
\hline Intrapersoonlijk & $\mathrm{r}=-.04$ & $\mathrm{r}=.57$ & $\mathrm{r}=-.35$ & $\mathrm{r}=-.01$ & $\mathrm{r}=.28$ & $\mathrm{r}=-.42$ \\
(BC) & $\mathrm{p}=.90$ & $\mathrm{p}=.03^{*}$ & $\mathrm{p}=.23$ & $\mathrm{p}=.98$ & $\mathrm{p}=.33$ & $\mathrm{p}=.14$ \\
Interpersoonlijk & $\mathrm{r}=.23$ & $\mathrm{r}=-.18$ & $\mathrm{r}=.30$ & $\mathrm{r}=.30$ & $\mathrm{r}=-.13$ & $\mathrm{r}=.13$ \\
(BC) & $\mathrm{p}=.43$ & $\mathrm{p}=.54$ & $\mathrm{p}=.29$ & $\mathrm{p}=.30$ & $\mathrm{p}=.66$ & $\mathrm{p}=.65$ \\
Intrapersoonlijk & $\mathrm{r}=-.06$ & $\mathrm{r}=.46$ & $\mathrm{r}=-.20$ & $\mathrm{r}=.23$ & $\mathrm{r}=-.21$ & $\mathrm{r}=.07$ \\
(PC) & $\mathrm{p}=.83$ & $\mathrm{p}=.10$ & $\mathrm{p}=.50$ & $\mathrm{p}=.44$ & $\mathrm{p}=.47$ & $\mathrm{p}=.81$ \\
Interpersoonlijk & $\mathrm{r}=-.14$ & $\mathrm{r}=-.34$ & $\mathrm{r}=.20$ & $\mathrm{r}=.05$ & $\mathrm{r}=.01$ & $\mathrm{r}=.12$ \\
(PC) & $\mathrm{p}=.63$ & $\mathrm{p}=.24$ & $\mathrm{p}=.49$ & $\mathrm{p}=.88$ & $\mathrm{p}=.97$ & $\mathrm{p}=.68$
\end{tabular}

$* \mathrm{p}<.05$

Emotionaliteit bleek door middel van een lineaire regressieanalyse een significante voorspeller van intra-persoonlijke correlatie in de basisconditie, $\mathrm{F}(1,13)=$ $5.85, \mathrm{p}=.03, \beta=26.92, \mathrm{n}=14)$.

Emotionaliteit verklaarde $32.8 \%$ van de variantie van interhemisferische correlatie in de basisconditie.

Er werd geen statistisch significante correlatie gevonden tussen de mate van overeenkomst in persoonlijkheid tussen twee proefpersonen in een koppel en interpersoonlijke correlatie; niet in de basisconditie $(r=-.62, n=7, p=.14)$ en niet in de praatconditie $(\mathrm{r}=-.02, \mathrm{n}=7, \mathrm{p}=$ $.98)$.

\section{Discussie}

Het doel van deze pilot studie was het onderzoeken of er sprake is van een relatie tussen persoonlijkheidsfactoren en intrapersoonlijke (interhemisferische) of interpersoonlijke EEG correlatie en of er sprake was van een relatie tussen de overeenkomst in persoonlijkheid en interpersoonlijke correlatie in hersenactiviteit.

De resultaten van huidig onderzoek laten zien dat er een relatie lijkt te bestaan tussen persoonlijkheid en connectiviteit van het brein: emotionaliteit is tijdens rust een significante voorspeller van intrapersoonlijke EEG correlatie. Wanneer wordt gecorrigeerd op multiple testen blijkt het gevonden resultaat niet significant. 
Labooy-Speksnijder et al. Persoonlijkheid en Hersenconnectiviteit, een nieuwe uitdaging?

Echter, de significante regressie indiceert dat er toch sprake kan zijn van een verband tussen emotionaliteit en intra-persoonlijke correlatie. Een hoge mate van emotionaliteit, gekenmerkt door overgevoeligheid, kwetsbaarheid, instabiliteit en onzekerheid [12] lijkt samen te hangen met een grotere samenwerking van beide hemisferen en mogelijk meer efficiënte uitvoering van taken. Er wordt verwacht dat deze relatie gemedieerd wordt door factoren als zelfbewustzijn, zelfwaardering en identiteit $[18,19]$, maar daarvoor is verder onderzoek noodzakelijk. Deze studie bevestigt eerdere onderzoeken dat persoonlijkheid in verband kan staant met diverse anatomische, functionele en biologische (brein)processen (e.g. [13, 14, 22]. Er is een specifieke persoonlijkheidsfactor gekoppeld aan een specifieke correlatiemaat, welke voor een klein gedeelte inzichtelijk maakt hoe individuele verschillen in connectiviteit van het brein eruit zien.

Er zijn echter minder relaties gevonden tussen persoonlijkheid en hersenactiviteit dan verwacht, en bovendien geen enkele in de conditie met sociale interactie en communicatie. In tegenstelling tot de verwachting werd er tevens geen correlatie gevonden tussen de samenhang in persoonlijkheid tussen twee proefpersonen in een koppel en interpersoonlijke EEG correlatie. Een verklaring hiervoor zou het tekort aan power kunnen zijn door de kleine steekproef, namelijk 14 proefpersonen (intra-persoonlijke correlatie) verdeeld over 7 koppels (interpersoonlijke correlatie). Daarnaast zijn de proefpersonen niet aselect gekozen en waren zij voor het testen al op de hoogte van het doel en de voortgang van het onderzoek. Ondanks de beperkingen is deze studie één van de eerste pogingen om een directe neurofysiologische relatie tussen connectiviteit en persoonlijkheid te achterhalen.

Toekomstig onderzoek met meer proefpersonen zal zich moeten richten op de ecologische validiteit en pogen situaties uit het dagelijks leven zoveel mogelijk te reproduceren, om de vertaalslag naar hedendaagse sociale interactie goed te kunnen maken. Hierbij kan mogelijk ook gecontroleerd worden voor de relatie die proefpersonen met elkaar hebben en hoe goed ze elkaar kennen.

Een grote uitdaging blijft het interpreteren van de gevonden correlaties tussen de activiteit in de breinen van interacterende personen [10]. Zodra meer onderzoek is gedaan zonder bovenstaande beperkingen kan worden gekeken naar toepasbaarheid van de bevindingen in therapie en overige 
Labooy-Speksnijder et al. Persoonlijkheid en Hersenconnectiviteit, een nieuwe uitdaging?

sociale situaties.

\section{Referenties}

1. Scholkmann, F., et al., A new methodical approach in neuroscience: assessing interpersonal brain coupling using functional near-infrared imaging (fNIRI) hyperscanning. Frontiers in human neuroscience, 2013. 7: p. 813.

2. Burgess, A.P., On the interpretation of synchronization in EEG hyperscanning studies: a cautionary note. Frontiers in human neuroscience, 2013. 7: p. 881.

3. Hasson, U., et al., Brain-to-brain coupling: a mechanism for creating and sharing a social world. Trends in cognitive sciences, 2012. 16(2): p. 114-121.

4. $\quad$ Engelbregt, H.J., et al., Brain Activity during joint and individual Mindfulness Meditation, a controlled EEG Study. IJTS, 2019.

5. Montague, P.R., et al., Hyperscanning: simultaneous fMRI during linked social interactions. 2002, Elsevier.

6. Gazzaniga, M.S., Cerebral specialization and interhemispheric communication: does the corpus callosum enable the human condition? Brain, 2000. 123(7): p. 1293-1326.

7. Ruchkin, D., EEG coherence. 2005.

8. Goede, N. and H. Engelbregt, $O p$ dezelfde golflengte. GGZ Vaktijdschrift GGZV, 2018. 1(2): p. 6-8.

9. Yun, K., On the same wavelength: Face-to-face communication increases interpersonal neural synchronization. Journal of Neuroscience, 2013. 33(12): p. 5081-5082.

10. Astolfi, L., et al., Imaging the Social Brain by Simultaneous
Hyperscanning During Subject Interaction. IEEE Intell Syst, 2011. 26(5): p. 38-45.

11. de Vries, R.E., K. Lee, and M.C. Ashton, The Dutch HEXACO Personality Inventory: psychometric properties, self-other agreement, and relations with psychopathy among low and high acquaintanceship dyads. J Pers Assess, 2008. 90(2): p. 142-51.

12. De Vries, R.E., M.C. Ashton, and $\mathrm{K}$. Lee, De zes belangrijkste persoonlijkheidsdimensies en de HEXACO

Persoonlijkheidsvragenlijst. 2009.

13. Adelstein, J.S., et al., Personality is reflected in the brain's intrinsic functional architecture. PloS one, 2011. 6(11): p. e27633.

14. Ryman, S.G., et al., Brain biochemistry and personality: a magnetic resonance spectroscopy study. PLoS one, 2011. 6(11): p. e26758.

15. Konareva, I., "Coronary" Type of Personality: Peculiarities of the Coherence of Ongoing EEG. Neurophysiology, 2012. 44(4): p. 314-321.

16. Hoppenbrouwers, S.S., et al., Personality goes a long a way: an interhemispheric connectivity study. Frontiers in psychiatry, 2010. 1: p. 140.

17. Engelbregt, H.J., et al., In-vivo EEG Changes During A Panic Attack in A Patient With Specific Phobia. Journal of Medical Cases, 2012. 3(1): p. 34-38.

18. Davies, M.F., Correlates of selfconsciousness and the 16 Personality Factor Questionnaire. The Journal of Psychology, 1982. 111(1): p. 123-128.

19. Silvia, P.J., Self-awareness and emotional intensity. Cognition \& Emotion, 2002. 16(2): p. 195-216. 
Labooy-Speksnijder et al. Persoonlijkheid en Hersenconnectiviteit, een nieuwe uitdaging?

20. Cooley, J.W. and J.W. Tukey, An algorithm for the machine calculation of complex Fourier series. Mathematics of computation, 1965. 19(90): p. 297301 .

21. De Vries, R.E. and M.P. Born, De Vereenvoudigde HEXACO Persoonlijkheidsvragenlijst en een additioneel interstitieel

Proactiviteitsfacet. Gedrag \& Organisatie, 2013. 26: p. 223-245.
22. DeYoung, C.G., et al., Testing predictions from personality neuroscience: Brain structure and the big five.

Psychological science, 2010. 21(6): p. 820828. 